\title{
Pengklasteran Dokumen Tentang Dispensasi Nikah Menggunakan Algoritma K-Medoids
}

\author{
Selfia Ningsih"1, Suhada', , Rafiqa Dewi ${ }^{3}$, Agus Perdana Windarto ${ }^{4}$ \\ Program Studi Sistem Informasi, STIKOM Tunas Bangsa Pematangsiantar \\ Jln. Jendral Sudirman Blok A No. 1,2,3 Pematangsiantar \\ selfianingsih01@gmail.com
}

\begin{abstract}
Marriage dispensation is the marriage of a prospective bride or groom who is underage and has not been approved to marry according to the regulations. In fact there are still many young women who are married under the age of 20 years. This study aims to determine the marriage dispensation cluster, because there is no research on clustering marriage dispensation documents using a computer method to cluster any area that often conducts marriage dispensations with high and low clusters. The research method used is Data Mining with the K-Medoids algorithm. Based on calculations using the K-Medoids algorithm, high cluster results of 22 sub-districts and low clusters were obtained in 8 subdistricts. The results obtained from this study are expected to be input to the government through socialization activities in order to reduce the number of marriage dispensation in each region.
\end{abstract}

Keywords: Datamining, K-Medoids Method, Marriage Dispensation Document

Abstrak - Dispensasi nikah merupakan perkawinan calon mempelai pria atau wanitanya masih di bawah umur dan belum diperbolehkan untuk menikah sesuai dengan peraturan. Kenyataannya masih banyak remaja putri yang menikah pada usia di bawah 20 tahun. Penelitian ini bertujuan untuk mengetahui cluster dispensasi nikah, karena belum adanya penelitian tentang pengklasteran dokumen dispensasi nikah dengan menggunkan metode komputer untuk mengklaster wilayah mana saja yang sering melakukan dispensasi nikah dengan cluster tinggi dan rendah. Metode penelitian yang digunakan adalah Data Mining dengan algoritma $K$-Medoids. Berdasarkan perhitungan menggunakan algoritma $K$ Medoids diperoleh hasil cluster tinggi sebanyak 22 kecamatan dan cluster rendah sebanyak 8 kecamatan. Dari hasil yang diperoleh penelitian ini diharapkan dapat menjadi masukan kepada pemerintah melalui kegiatan sosialisasi agar dapat mengurangi angka dispensasi nikah disetiap wilayah.

Kata kunci: Datamining, Metode K-Medoids, Dokumen Dispensasi Nikah

\section{PENDAHULUAN}

Seiring perkembangan zaman banyak teknologi yang telah banyak membantu manusia untuk menyelesaikan suatu masalah. Hal inilah yang mendorong adanya algoritma-algoritma dari Data Mining. Salah satunya adalah Algoritma K-Medoidsyang merupakan metode dalam teknik clustering. Algoritma $K$-Medoids hadir untuk mengatasi kelemahan Algoritma $K$-Means yang sensitif terhadap outlier karena suatu objek dengan suatu nilai yang besar mungkin secara substansial menyimpang dari distribusi data.K-Medoids memiliki komputasi yang cepat dibanding dengan $\mathrm{K}$-Means sehingga modifikasi nya lebih efektif digunakan [1]. 
Di pengadilan agama simalungun terdapat banyak perkara diantaranya cerai gugat, cerai talak, dispensasi nikah, isbat nikah dan lain sebagainya. Penulis mengambil salah satu perkara tersebut untuk dijadikan judul skripsi yaitu dispensasi nikah. Dispensasi nikah merupakan perkawinan calon mempelai pria atau wanitanya masih di bawah umur dan belum diperbolehkan untuk menikah sesuai dengan peraturan. Pemerintah menetapkan usia ideal menikah untuk pria berumur 19 tahun dan untuk wanita 16 tahun. Dampak dari dispensasi nikah yaitu kondisi emosional anak remaja yang masih belum stabil dan juga akan kehilangan masa depan ataupun pekerjaan yang layak sehingga kurang terjamin kehidupan mereka nantinya. Pengklasteran dokumen tentang dispensasi nikah belum diketahui dengan menggunakan metode komputer sehingga diperlukan nya penelitian ini untuk mengetahui cluster-cluster pada tingkat tinggi dan rendah.

Penulis menggunakan algoritma K-Medoids sebagai metode untuk mengklaster kecamatan pada tingkat tinggi dan rendah. Agar nantinya pemerintah bisa menanggulangi wilayah yang masih banyak terjadi dispensasi nikah dan bisa mengantisipasi wilayah tersebut supaya tidak terlalu banyak terjadi perkara dispensasi nikah. Pengklasteran dilakukan dengan cara mengumpulkan data untuk membuat kedalam duacluster, dalam pembuatan cluster digunakan metode $K$ Medoids agar dapat diperoleh dua cluster tersebut. Berbagai penelitian telah dilakukan dalam pemanfaatan metode Data Mining khususnya Clustering dalam melakukan pengelompokkan data yang dituliskan dalam jurnal atau karya ilmiah. Beberapa diantaranya yaitu :[2]dalam penelelitiannya "Penerapan Algoritma Partitioning Around Medoids (PAM)Clustering Untuk Melihat Gambaran Umum KemampuanAkademik Mahasiswa" yang menghasilkan gambaran umum kemampuan akademik data akademik yang diperolehnya. Data yang digunakan merupakan data akademik mahasiswa jurusan Informatika Unjani selama 6 semester sebanyak 100 orang dengan jumlah cluster sebanyak 3 cluster, dimana cluster tersebut akan mewakili tingkat kemampuan akademik. Pengukuran mutu cluster menggunakan Silhouette. Dan penelitian yang dilakukan oleh [3] yang berjudul "Perancangan Dan Analisis Clustering Data Menggunakan Metode KMedoids Untuk Berita Berbahasa Inggris Design And Analysis Of Data Clustering Using K-Medoids Method For English News" yang diketahui hasil summary dari berita pertama yang mempunyai nilai rangking 2.4082399653118496 dan berita kedua yang mempunyai nilai rangking 3.4614262661931448 dan sesuai dengan penentuan kalimat utama dalam website tersebut.

Berdasarkan latar belakang masalah diatas, maka penulis mengambil judul yaitu Pengklasteran Dokumen Tentang Dispensasi Nikah Menggunakan Algoritma K-Medoids diharapkan penelitian ini dapat mengetahui cluster dispensasi nikah pada tingkat tinggi dan rendah sehingga dapat menjadi masukan kepada pemerintah melalui kegiatan sosialisasi agar dapat mengurangi angka dispensasi nikah disetiap wilayah.

\section{METODOLOGI PENELITIAN}

\subsection{Analisa Data}

Dalam melakukan penelitian ini, analisis data yang digunakan adalah data kuantitatif dengan teknik analisis data yang menggunakan jenis statistic deskriptif. 
Penelitian ini dilakukan di Pengadilan Agama Simalungun. Data penelitian diperoleh dengan melakukan wawancara dan observasi kepada pihak instansi. Data yang terkumpul selanjutnya diolah menggunakan algoritma $k$-medoids. Kemudian diuji dengan tools RapidMiner menggunakan Performance yang berfungsi sebagai validasi dan reabilitas data untuk mencari keakuratan data. Perancangan diagram flowchart penelitian ditunjukkan dalam gambar 1:

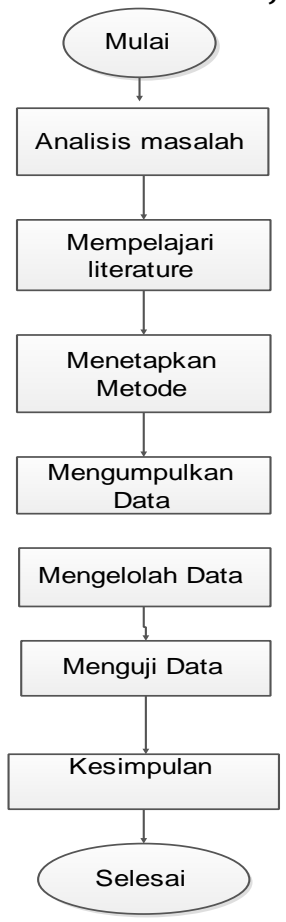

Gambar 1. Perancangan Penelitian

\subsection{Data Mining}

Data mining didefinisikan sebagai proses yang menggunakan teknikstatistik, matematika, kecerdasan buatan, dan machine learning untuk mengekstraksi dan mengidentifikasi informasi yang bermanfaat dan pengetahuan yangterkait dari berbagai database besar. Istilah data mining memiliki hakikat sebagai disiplin ilmu yang tujuan utamanya adalah untuk menemukan, menggali, atau menambang pengetahuan dari data atau informasiyang kita miliki [4].

Data mining adalah salah satu cabangilmu komputer yang banyak menarik perhatian masyarakat. Data mining adalah tumpukan datayang sudah tersimpan selama bertahun-tahun yang dimasukkan kedalam database tetapi tidak digunakan kembali atau disebut "data sampah".Data mining digunakan untuk menggali danmendapatkan informasi dari data denganjumlah besar [5].Data Mining sering disebut Knowledge Discovery in Database (KDD). Data Mining biasanya digunakan untuk memperbaiki pengambilan keputusan di masa yang akan datang berdasarkan informasi yang diperoleh dari masa lalu. Misalnya untuk prediksi, estimasi, assosiasi, Clustering, dan deskripsi. 


\subsection{Algoritma $K$-Medoids}

Algoritma $k$-medoids mempunyai kesamaan dengan metode $k$-means yaitu sama-sama termasuk metode partitioning. Metode partitioning merupakan metode pengelompokan data ke dalam sejumlah cluster tanpa adanya struktur hirarki antara satu dengan yang lainnya. Metode $k$-medoids memiliki keunggulan dibandingkan dengan metode $k$-means. $K$-medoids memiliki kinerja yang lebih optimal jika jumlah data yang digunakan berjumlah sedikit. Algoritma ini menggunakan objek pada kumpulan objek untuk mewakili sebuah cluster [6].

K-Medoid menggunakan $k$ sebagai jumlahpusat cluster awal yang dihasilkan secara acak diawal proses clustering. Setiap obyek yang lebih dekat dengan pusat cluster akan dikelompokkan dan membentuk cluster baru. Algoritma kemudian secara acak menentukan cluster center baru dari setiap cluster yang terbentuk sebelumnya dan menghitung ulang jarak antara obyek dan pusat cluster baru yang dihasilkan. Jarak antar obyek $i$ dan $j$ dihitung dengan menggunakan dissimilarity measurement function, dimana salah satunya adalah Euclidean Distance Function yang ditunjukkan dalam persamaan berikut [7]

$d(x, y)=\sqrt{\sum_{i=1}^{n}|x i-y i|^{2}}$

Dimana:

$\mathrm{d}(\mathrm{x}, \mathrm{y})=$ jarak antara data ke-i dan data ke-j

xi1 = nilai atribut ke satu dari data ke-i

yj1 = nilai atribut ke satu dari data ke-j

$\mathrm{n}=$ jumlah atribut yang digunakan

K-Medoids Clustering hadir untuk mengatasi kelemahan $K$-Means Clustering yang sensitiveterhadapoutlier karena suatu objek dengan suatu nilai yang besar mungkin secara substansial menyimpangdaridistribusi data. Adapuntahapan $K$ Medoids Clustering adalah berikut [8] :

1. Secara acak pilih $k$ objek pada sekumpulan $n$ objek sebagai medoid.

2. Ulangi.

3. Tempatkan objek nonmedoid ke dalam klaster yang paling dekat dengan medoid.

4. Secara acak pilih Orandom (sebuah objek non medoid).

5. Hitung total cost, $S$, dari pertukaran medoid Oj dengan Orandom.

6. Jika $S<0$ maka tukar $O$ j dengan Orandom untuk membentuk sekumpulan $k$ objek baru sebagai medoid.

7. Ulangi hingga tidak ada perubahan.

\section{HASIL DAN PEMBAHASAN}

\subsection{Analisis Algoritma $K$-Medoids}

Pada tahapan ini pengolahan data dispensasi nikah berdasarkan kecamatan menggunakan algoritma $k$-medoids. Berikut adalah data dispensasi nikah yang diambil penulis langsung dari instansi. 
Tabel 1. Data Penelitian

\begin{tabular}{|c|c|c|c|c|}
\hline No & Kecamatan & Pergaulan Bebas & Ekonomi & Keinginan Sendiri \\
\hline 1 & Tapian dolok & 28 & 25 & 22 \\
\hline 2 & Lima Puluh & 15 & 14 & 15 \\
\hline 3 & Bandar & 21 & 16 & 15 \\
\hline 4 & Pematang Bandar & 14 & 16 & 16 \\
\hline 5 & D.Batu Nanggar & 17 & 18 & 19 \\
\hline 6 & Bosar Maligas & 23 & 22 & 19 \\
\hline 7 & Bandar Huluan & 23 & 23 & 18 \\
\hline 8 & Siantar & 14 & 16 & 16 \\
\hline 9 & Gunung Maligas & 19 & 19 & 19 \\
\hline 10 & Tanah Jawa & 17 & 16 & 20 \\
\hline 11 & P.Sidamanik & 29 & 25 & 21 \\
\hline 12 & Gunung Malela & 26 & 23 & 19 \\
\hline 13 & J.Maraja Bahjambi & 14 & 17 & 15 \\
\hline 14 & Bandar Masilam & 15 & 15 & 17 \\
\hline 15 & Huta Bayu Raja & 25 & 23 & 19 \\
\hline 16 & Hatonduhan & 21 & 20 & 19 \\
\hline 17 & Ujung Padang & 29 & 24 & 20 \\
\hline 18 & Jarlang Hataran & 21 & 20 & 19 \\
\hline 19 & Dolok Panribuan & 12 & 12 & 11 \\
\hline 20 & G.Sipangan Bolon & 25 & 24 & 18 \\
\hline 21 & Sidamanik & 28 & 26 & 23 \\
\hline 22 & Pane & 27 & 24 & 19 \\
\hline 23 & Panambean Panei & 19 & 14 & 11 \\
\hline 24 & Raya & 30 & 28 & 24 \\
\hline 25 & Purba & 29 & 25 & 20 \\
\hline 26 & H.Horison & 13 & 13 & 12 \\
\hline 27 & Silimakuta & 24 & 21 & 18 \\
\hline 28 & P.Silimahuta & 28 & 26 & 19 \\
\hline 29 & Raya Kahean & 23 & 21 & 18 \\
\hline 30 & Dolok Pardamean & 22 & 19 & 17 \\
\hline 31 & Dolok Silau & 28 & 26 & 23 \\
\hline 32 & Silau Kahean & 24 & 20 & 18 \\
\hline
\end{tabular}

Langkah-langkah dalam menyelesaikan perhitungan manual data mining menggunakan $k$-medoids clustering adalah sebagai berikut.

1. Inisialisasi pusat cluster sebanyak 2 cluster dari data sampel.

Untuk pemilihan setiap medoid dipilih secara acak (random). Berikut data acak yang dipilih.

Tabel 2. Medoid Awal

\begin{tabular}{|l|l|c|c|c|}
\hline \multicolumn{1}{|c|}{ Nama } & Keterangan & X & Y & Z \\
\hline Bandar Masilam & Diambil data ke 14 sebagai pusat cluster & 15 & 15 & 17 \\
\hline Silau Kahean & Diambil data ke 32 sebagai pusat cluster & 24 & 20 & 18 \\
\hline
\end{tabular}

Untuk menghitung jarak antara titik centroid dengan titik tiap objek menggunakan rumus persamaan (2.3). Maka perhitungan antara jarak pada medoid ke-1 adalah sebagai berikut.

$D_{\text {Tapian DolokC } 1}=\sqrt{\left((28-15)^{2}+(25-15)^{2}(22-17)^{2}\right.}=17,1464282$

Pengklasteran Dokumen Tentang Dispensasi Nikah Menggunaka K-Medoids (Selfia Ningsih) |681 
$D_{\text {Tapian DolokC2 }}=\sqrt{\left((28-24)^{2}+(25-20)^{2}(22-18)^{2}\right.}=7,549834435$

$D_{\text {Bandar MasilamC } 1}=\sqrt{\left((15-15)^{2}+(15-15)^{2}(17-17)^{2}\right.}=0$

$D_{\text {Bandar MasilamC2 }}=\sqrt{\left((15-24)^{2}+(15-20)^{2}(17-18)^{2}\right.}=10,34408043$

$D_{\text {Silau KaheanC } 1}=\sqrt{\left((24-15)^{2}+(20-15)^{2}(18-17)^{2}\right.}=10,34408043$

$D_{\text {Silau KaheanC } 2}=\sqrt{\left((24-24)^{2}+(20-20)^{2}(18-18)^{2}\right.}=0$

Maka didapatkan hasil keseluruhan dari iterasi pertama dan dapat dilihat pada tabel berikut.

Tabel 3. Hasil Perhitungan Algoritma K-Medoids Iterasi ke-1

\begin{tabular}{|c|c|c|c|c|c|}
\hline \multirow[t]{2}{*}{ No } & \multirow[t]{2}{*}{ Data ke-i } & \multicolumn{2}{|c|}{ Jarak ke Medoids } & \multirow[t]{2}{*}{ Terdekat } & \multirow{2}{*}{$\begin{array}{c}\text { Cluster yang } \\
\text { Mendekati }\end{array}$} \\
\hline & & C1 & $\mathrm{C2}$ & & \\
\hline 1 & Tapian dolok & 17,1464282 & 7,549834435 & 7,549834435 & 1 \\
\hline 2 & Lima Puluh & 2,236067977 & 11,22497216 & 2,236067977 & 0 \\
\hline 3 & Bandar & 6,403124237 & 5,830951895 & 5,830951895 & 0 \\
\hline 4 & Pematang Bandar & 1,732050808 & 10,95445115 & 1,732050808 & 0 \\
\hline 5 & Dolok Batu Nanggar & 4,123105626 & 7,348469228 & 4,123105626 & 0 \\
\hline 6 & Bosar Maligas & 10,81665383 & 2,449489743 & 2,449489743 & 1 \\
\hline 7 & Bandar Huluan & 11,35781669 & 3,16227766 & 3,16227766 & 1 \\
\hline 8 & Siantar & 1,732050808 & 10,95445115 & 1,732050808 & 0 \\
\hline 9 & Gunung Maligas & 6 & 5,196152423 & 5,196152423 & 1 \\
\hline 10 & Tanah Jawa & 3,741657387 & 8,306623863 & 3,741657387 & 0 \\
\hline$\ldots$ & $\ldots$ & $\ldots$ & $\ldots$ & $\ldots$ & $\ldots$ \\
\hline 30 & Dolok Pardamean & 8,062257748 & 2,449489743 & 2,449489743 & 1 \\
\hline 31 & Dolok Silau & 18,05547009 & 8,774964387 & 8,774964387 & 1 \\
\hline 32 & Silau Kahean & 10,34408043 & 0 & 0 & 1 \\
\hline & Jumlah & 325,7825381 & 220,7549701 & & \\
\hline & Total Cost & 546,5 & 75082 & & \\
\hline
\end{tabular}

2. Setelah didapatkan hasil dari setiap objek di iterasi pertama, maka lanjut ke iterasi kedua. Kandidat Medoid baru (non-Medoid) pada iterasi kedua bisa dilihat sebagai berikut.

Tabel 4. Medoid baru(Non-Medoid) Iterasi Ke-2

\begin{tabular}{|l|l|c|c|c|}
\hline \multicolumn{1}{|c|}{ Nama } & \multicolumn{1}{|c|}{ Keterangan } & X & Y & Z \\
\hline Bosar Maligas & Diambil data ke 6 sebagai pusat cluster & 23 & 22 & 19 \\
\hline Jarlang Hataran & Diambil data ke 18 sebagai pusat cluster & 21 & 20 & 19 \\
\hline
\end{tabular}

$D_{\text {Tapian DolokC1 }}=\sqrt{\left((28-23)^{2}+(25-22)^{2}(22-19)^{2}\right.}=6,5574385243$

$D_{\text {Tapian DolokC2 }}=\sqrt{\left((28-21)^{2}+(25-20)^{2}(22-19)^{2}\right.}=9,1104335791$

$D_{\text {Bosar MaligasC } 1}=\sqrt{\left((23-23)^{2}+(22-22)^{2}(19-19)^{2}\right.}=0$

$D_{\text {Bosar MaligasC } 2}=\sqrt{\left((23-21)^{2}+(22-20)^{2}(19-19)^{2}\right.}=2,828427125$

$D_{\text {Jarlang HataranC } 1}=\sqrt{\left((21-23)^{2}+(20-22)^{2}(19-19)^{2}\right.}=2,828427125$

$D_{\text {Jarlang HataranC } 2}=\sqrt{\left((21-21)^{2}+(20-20)^{2}(19-19)^{2}\right.}=0$ 
Tabel 5. Hasil Perhitungan Algoritma K-Medoid Iterasi ke-2

\begin{tabular}{|c|l|c|c|c|c|}
\hline \multirow{2}{*}{ No } & \multicolumn{1}{|c|}{ Data ke-i } & \multicolumn{2}{c|}{ Jarak ke medoids } & Terdekat & $\begin{array}{c}\text { Cluster yang } \\
\text { Mendekati }\end{array}$ \\
\cline { 3 - 4 } & & $\mathbf{C 1}$ & $\mathbf{C 2}$ & & 0 \\
\hline 1 & Tapian dolok & 12 & 9,38083152 & 9,38083152 & 1 \\
\hline 2 & Lima Puluh & 7,483314774 & 5,656854249 & 5,656854249 & 1 \\
\hline 3 & Bandar & 11,22497216 & 8,602325267 & 8,602325267 & 1 \\
\hline 4 & Pematang Bandar & 7,211102551 & 4,472135955 & 4,472135955 & 1 \\
\hline 5 & Dolok Batu Nanggar & 0 & 2,828427125 & 0 & 0 \\
\hline 6 & Bosar Maligas & 1,414213562 & 3,741657387 & 1,414213562 & 0 \\
\hline 7 & Bandar Huluan & 11,22497216 & 8,602325267 & 8,602325267 & 1 \\
\hline 8 & Siantar & 5 & 2,236067977 & 2,236067977 & 1 \\
\hline 9 & Gunung Maligas & 8,544003745 & 5,744562647 & 5,744562647 & 1 \\
\hline 10 & Tanah Jawa & $\ldots$ & $\ldots$ & & $\ldots$ \\
\hline$\ldots$ & $\ldots$ & 3,741657387 & 2,449489743 & 2,449489743 & 1 \\
\hline 30 & Dolok Pardamean & 7,549834435 & 10,04987562 & 7,549834435 & 0 \\
\hline 31 & Dolok Silau & 2,449489743 & 3,16227766 & 2,449489743 & 0 \\
\hline 32 & Silau Kahean & 216,6108094 & 220,0756807 & & \\
\hline Iumlahnnnnnn \\
\hline Total Cost & \multicolumn{2}{|c|}{436,68649} & & \\
\hline
\end{tabular}

Setelah didapatkan nilai jarak antara iterasi ke-1 dan ke-2, hitung total simpangan dengan mencari selisih dari nilai cost baru dan cost lama.

$\mathrm{S}=$ Total cost baru-Total cost lama

$=436,68649-546,5375082$

$=-109,851$

3. Lanjut iterasi ketiga karena hasil cost masih bernilai minus.

Tabel 6. Medoid Baru(Non-Medoid 2) Iterasi ke-3

\begin{tabular}{|l|l|c|c|c|}
\hline Nama & Keterangan & X & Y & Z \\
\hline Haranggaol Horison & Diambil data ke 2 sebagai pusat cluster & 13 & 13 & 12 \\
\hline Silimakuta & Diambil data ke 3 sebagai pusat cluster & 24 & 20 & 18 \\
\hline
\end{tabular}

$D_{\text {Tapian DolokC1 }}=\sqrt{\left((28-13)^{2}+(25-13)^{2}(22-12)^{2}\right.}=21,65640783$

$D_{\text {Tapian DolokC2 }}=\sqrt{\left((28-24)^{2}+(25-20)^{2}(22-18)^{2}\right.}=7,549834435$

$D_{\text {Haranggaol HorisonC } 1}=\sqrt{\left((13-13)^{2}+(13-13)^{2}(12-12)^{2}\right.}=0$

$D_{\text {Harang gaol HorisonC } 2}=\sqrt{\left((13-24)^{2}+(13-20)^{2}(12-18)^{2}\right.}=14,35270009$

$D_{\text {SilimakutaC } 1}=\sqrt{\left((24-13)^{2}+(20-13)^{2}(18-12)^{2}\right.}=14,86606875$

$D_{\text {SilimakutaC } 2}=\sqrt{\left((24-24)^{2}+(20-20)^{2}(18-18)^{2}\right.}=1$

Tabel 7. Data Perhitungan Algoritma K-Medoids Hasil Iterasi Ke-3

\begin{tabular}{|l|l|c|c|c|c|}
\hline \multirow{2}{*}{ No } & \multicolumn{1}{|c|}{ Data ke-i } & \multicolumn{2}{|c|}{ Jarak ke medoids } & Terdekat & $\begin{array}{c}\text { Cluster yang } \\
\text { Mendekati }\end{array}$ \\
\cline { 3 - 5 } & & C1 & C2 & & 1 \\
\hline 1 & Tapian dolok & 21,65640783 & 7,549834435 & 7,549834435 & 0 \\
\hline 2 & Lima Puluh & 3,741657387 & 11,22497216 & 3,741657387 & 1 \\
\hline 3 & Bandar & 9,055385138 & 5,830951895 & 5,830951895 & 0 \\
\hline 4 & Pematang Bandar & 5,099019514 & 10,95445115 & 5,099019514 & 1 \\
\hline 5 & Dolok Batu Nanggar & 9,486832981 & 7,348469228 & 7,348469228 & 1 \\
\hline 6 & Bosar Maligas & 15,16575089 & 2,449489743 & 2,449489743 & 1 \\
\hline 7 & Bandar Huluan & 15,3622915 & 3,16227766 & 3,16227766 & 1 \\
\hline
\end{tabular}

Pengklasteran Dokumen Tentang Dispensasi Nikah Menggunaka K-Medoids (Selfia Ningsih) |683 


\begin{tabular}{|c|l|c|c|c|c|}
\hline \multirow{2}{*}{ No } & \multicolumn{1}{|c|}{ Data ke-i } & \multicolumn{2}{c|}{ Jarak ke medoids } & Terdekat & $\begin{array}{c}\text { Cluster yang } \\
\text { Mendekati }\end{array}$ \\
\cline { 3 - 6 } & & C1 & C2 & & 0 \\
\hline 8 & Siantar & 5,099019514 & 10,95445115 & 5,099019514 & 1 \\
\hline 9 & Gunung Maligas & 11 & 5,196152423 & 5,196152423 & 1 \\
\hline 10 & Tanah Jawa & 9,433981132 & 8,306623863 & 8,306623863 & $\ldots$ \\
\hline$\ldots$ & $\ldots$ & $\ldots$ & $\ldots$ & $\ldots$ & 1 \\
\hline 30 & Dolok Pardamean & 11,91637529 & 2,449489743 & 2,449489743 & 1 \\
\hline 31 & Dolok Silau & 22,69361144 & 8,774964387 & 8,774964387 & 1 \\
\hline 32 & Silau Kahean & 14,35270009 & 0 & & \\
\hline Jumlah & 432,5624622 & 220,7549701 & & \\
\hline \multicolumn{2}{|c|}{ Total Cost } & 653,3174322 & & \\
\hline
\end{tabular}

Setelah diperoleh total cost dengan hasil positif maka tidak dilakukan lagi perulangan iterasi. Berikut adalah hasil total simpangan dari iterasi ke-3.

$$
\begin{aligned}
\text { S } & =\text { Total cost baru-Total cost lama } \\
& =653,3174322-436,68649 \\
& =216,6309422
\end{aligned}
$$

Sum (C1) Cluster Rendah = 8

Sum (C2) Cluster Tinggi $=24$

\subsection{Hasil}

Berdasarkan dari perhitungan diatas maka diperoleh hasil cluster rendah sebanyak 8 kecamatan dan cluster tinggi sebanyak 24 kecamatan, dan berikut adalah hasil dari cluster tinggi dan rendah, dapat dilihat pada tabel berikut:

Tabel 8. Kecamatan Cluster Tinggi dan Rendah

\begin{tabular}{|c|l|l|}
\hline No & Kecamatan Cluster Tinggi & Kecamatan Cluster Rendah \\
\hline 1. & Tapian Dolok & Lima Puluh \\
\hline 2. & Bandar & Pematang Bandar \\
\hline 3. & Dolok Batu Nanggar & Bandar Huluan \\
\hline 4. & Bosar Maligas & Jawa Maraja Bahjambi \\
\hline 5. & Bandar Huluan & Bandar Masilam \\
\hline 6. & Gunung Maligas & Dolok Panribuan \\
\hline 7. & Tanah Jawa & Panambean Panei \\
\hline 8. & Pematang Sidamanik & Haranggaol Horison \\
\hline 9. & Gunung Malela & - \\
\hline 10. & Huta Bayu Raja & - \\
\hline 11. & Hatonduhan & - \\
\hline 12. & Ujung Padang & - \\
\hline 13. & Jarlang Hataran & - \\
\hline 14. & Girsang Sipangan Bolon & - \\
\hline 15. & Sidamanik & - \\
\hline 16. & Pane & - \\
\hline 17. & Raya & - \\
\hline 18. & Purba & - \\
\hline 19. & Silimakuta & - \\
\hline 20. & Pematang Silimahuta & - \\
\hline 21. & Raya Kahean & - \\
\hline 22. & Dolok Pardamean & - \\
\hline
\end{tabular}




\begin{tabular}{|l|l|l|}
\hline No & Kecamatan Cluster Tinggi & Kecamatan Cluster Rendah \\
\hline 23. & Dolok Silau & - \\
\hline 24. & Silau Kahean & - \\
\hline
\end{tabular}

Berikut adalah hasil dari pengujian menggunakan tools RapidMiner:

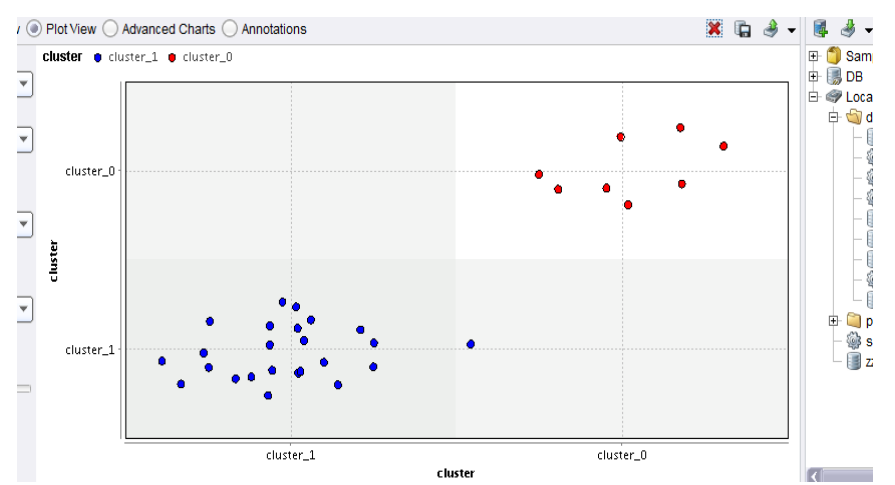

Gambar 2. Grafik Pengelompokkan

Berdasarkan pada gambar 4.13. dapat diketahui bahwa pada titik berwarna Biru (Tinggi) memiliki banyak node yaitu 24, sedangkan pada titik berwarna Merah (Rendah) hanya memiliki 8 node.

\subsection{Pembahasan}

Berdasarkan dari penjelasan diatas mengenai implementasi $k$-medoids serta hasil yang sudah ditampilkan, berikut pembahasan mengenai keterkaitan dari hasil yang didapat antara perhitungan manual $k$-medoids dengan hasil yang ditampilkan oleh Rapidminer. Data yang telah dianalisa maka disimpulkan bahwa data yang digunakan adalah valid. Hal ini dibuktikan dengan dilakukannya perhitungan manual dan data uji dari Rapidminer 5.3 yang dapat menampilkan hasil yang sama. Tampilan data cluster model berupa teks yang ada di Rapidminer bisa dilihat pada gambar 3. sebagai berikut.

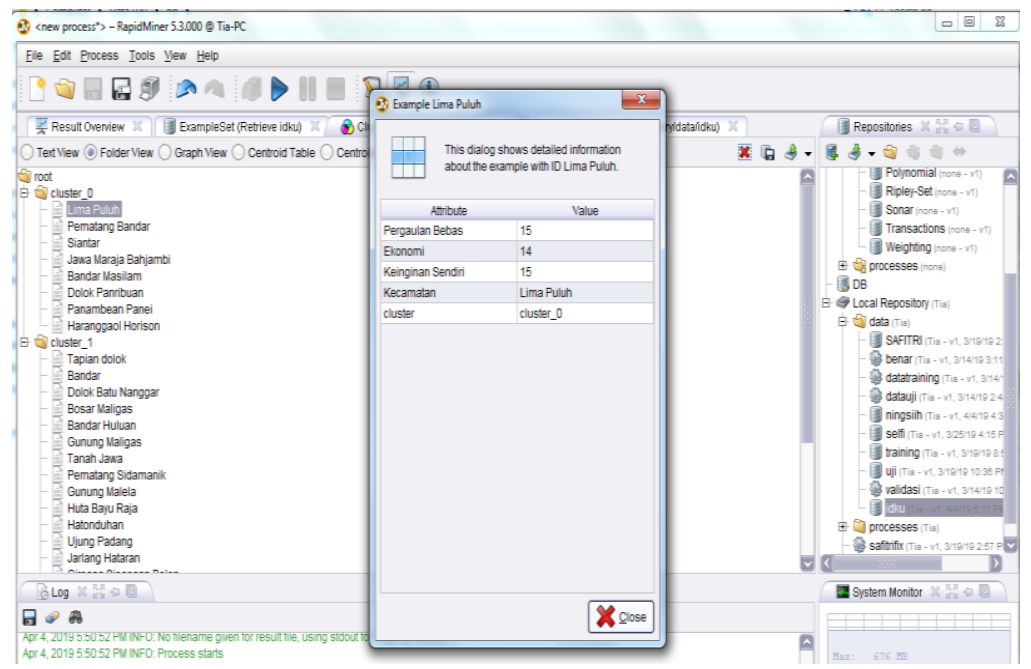

Gambar 3. Folder View Dispensasi Nikah 


\section{KESIMPULAN}

Berdasarkan pembahasan sebelumnya dapat disimpulkan bahwa:

1. Penerapan Data mining dengan menggunakan algoritma $k$-medoids dalam pengklasteran dokumen dispensasi nikah dengan data sebanyak 32 kecamatan maka diperoleh pengklasteran dengan kelas Rendah sebanyak 8 dan kelas Tinggi sebanyak 24 kecamatan.

2. Pengujian data pada Rapidminer 5.3 menggunakan $k$-medoids dapat menampilkan dua kelas dari hasil pengklasteran yang sesuai dengan perhitungan manual.

3. Metodologi yang dipakai dalam pengumpulan datanya menggunakan metode sampling yaitu mengambil sebagian data untuk diteliti.

\section{DAFTAR PUSTAKA}

[1] W. A. Triyanto, “Algoritma K-Medoids Untuk Penentuan Strategi Pemasaran,” Vol. 6, No. 1, Pp. 183-188, 2015.

[2] Y. H. Chrisnanto And G. Abdillah, "Penerapan Algoritma Partitioning Around Medoids ( Pam ) Clustering Untuk Melihat Gambaran Umum Kemampuan,” Vol. 2015, No. Sentika, Pp. 444448, 2015.

[3] H. Zayuka, S. M. Nasution, And Y. Purwanto, "Perancangan Dan Analisis Clustering Data Menggunakan Metode K-Medoids Untuk Berita Berbahasa Inggris Design And Analysis Of Data Clustering Using K-Medoids Method," Vol. 4, No. 2, Pp. 2182-2190, 2017.

[4] M. Ridwan, H. Suyono, And M. Sarosa, "Penerapan Data Mining Untuk Evaluasi Kinerja Akademik Mahasiswa Menggunakan Algoritma Naive Bayes Classifier,” J. Eeccis, Vol. 7, No. 1, Pp. 59-64, 2013.

[5] Evicienna And H. Amalia, "Algoritma C4.5 Untuk Prediksi Hasil Pemilihan Legislatif Dprd Dki Jakarta 1 1,2,” Vol. Ix, No. 1, Pp. 48-56, 2013.

[6] A. Y. Rofiqi, "Clustering Berita Olahraga Berbahasa Indonesia Menggunakan Metode KMedoid," Vol. 6, No. 1, 2017.

[7] M. T. Furqon, A. Ridok, And W. F. Mahmudy, "Paralelisasi Algoritma K-Medoid Pada Gpu," Pp. 408-413, 2015.

[8] Y. H. Susanti And E. Widodo, "Perbandingan K-Means Dan K-Medoids Clustering Terhadap Kelayakan Puskesmas Di Diy Tahun 2015,” Vol. 1, No. 1, Pp. 116-122, 2017. 